\title{
Combination of serum microRNAs and ultrasound profile as predictive biomarkers of diagnosis and prognosis for papillary thyroid microcarcinoma
}

\author{
YANQING ZHANG $^{1 *}$, JIAQI PAN $^{1 *}$, DESHENG XU ${ }^{2}$, ZHENGKAI YANG $^{3}$, \\ JINGXUE SUN ${ }^{4}$, LULU SUN ${ }^{4}$, YANMEIZHI WU ${ }^{4}$ and HONG QIAO ${ }^{4}$ \\ ${ }^{1}$ Department of Hematology, The Second Affiliated Hospital of Harbin Medical University, Harbin, Heilongjiang 150001; \\ ${ }^{2}$ Department of Anaesthesiology, The Cancer Hospital Affiliated to Harbin Medical University; ${ }^{3}$ Clinical Laboratory, \\ First Affiliated Hospital, Heilongjiang University of Chinese Medicine, Harbin, Heilongjiang 150040; \\ ${ }^{4}$ Department of Endocrinology, The Second Affiliated Hospital of Harbin Medical University, \\ Harbin, Heilongjiang 150001, P.R. China
}

Received April 30, 2018; Accepted September 21, 2018

DOI: $10.3892 /$ or.2018.6776

\begin{abstract}
Circulating microRNAs (miRNAs) are promising diagnostic markers in various types of cancers, including papillary thyroid carcinoma (PTC). However, there is sparse information reported with regards to miRNA expression in papillary thyroid microcarcinoma (PTMC) or concerning the role of a combination of miRNAs and ultrasound (US) in the diagnosis of PTMC before surgery. Therefore, we designed a study that aimed to evaluate miRNA expression levels and their potential associations with US findings and determine whether miRNAs could be used as diagnostic and prognostic biomarkers of PTMC. miR-222, miR-221, miR-146b and miR-21 levels were determined using reverse transcription-quantitative polymerase chain reaction (RT-qPCR) in serum from 58 patients with PTMC and 47 with PTC, 35 patients with benign thyroid nodules (BTN) and 40 control subjects. Expression levels of the four miRNAs in serum were evaluated before and after surgery. The results indicated that miR-222, miR-221, miR-146b and miR-21 expression levels were higher in the PTMC samples than in those from the BTN and control groups and the combination of miRNAs and US had a high sensitivity and specificity for discrimination between BTN and PTMC by receiver operating characteristic (ROC) curve analysis and improved the accuracy of diagnosis of PTMC before surgery. In addition, serum miRNA expression levels were significantly related to poor prognostic factors including metastatic lymph nodules (MLNs), multifocal and
\end{abstract}

Correspondence to: Dr Hong Qiao, Department of Endocrinology, The Second Affiliated Hospital of Harbin Medical University, 246 Xuefu Road, Nangang, Harbin, Heilongjiang 150001, P.R. China E-mail: qiaoh0823@sina.com

\section{${ }^{*}$ Contributed equally}

Key words: papillary thyroid microcarcinoma, microRNA, diagnosis, prognosis, ultrasound bilateral lesions, advanced stage and high-risk PTMC patients. The miRNA expression levels in serum from PTMC patients were rapidly reduced after surgery compared with levels before surgery. In addition, we also analyzed the miRNA expression levels in serum from patients who were divided into two groups according to factors indicating a good or poor prognosis associated with PTMC after surgery. The results suggested that after surgery, the miR-222, miR-146b and miR-21 expression levels were significantly higher in the poor prognosis group compared with these levels in the good prognosis group. Serum miRNA expression levels helped distinguish between benign and malignant nodules and were associated with a poor prognosis in PTMC. Circulating miRNAs may be useful as follow-up biomarkers and as diagnostic and prognostic tools.

\section{Introduction}

Papillary thyroid microcarcinoma (PTMC) is a subtype of papillary thyroid carcinoma (PTC), which is defined by the WHO as measuring $1.0 \mathrm{~cm}$ or less in the greatest dimension of the tumor (1). There is a well-documented, worldwide trend showing an rapid increasing incidence of PTC in recent decades (2-4). This increase has been predominantly an increase in PTMC, accounting for 50\% of PTCs (5-7).

High-resolution ultrasound (US) is a widespread technique used as a first-line diagnostic tools for PTMC before surgery. Although certain US findings are suggestive of malignancy, their predictive value is inconsistent, and the accumulated predictive value of US characteristics and basic clinical features range between 30 and $48 \%$ (8). A recent study has reported that $17.2-22.6 \%$ of nodules were finally confirmed as benign despite the presence of suspicious US features $(9,10)$. US-guided fine-needle aspiration biopsy (US-FNAB) is currently the most important method for determining a diagnosis of PTMC and could serve as a supplemental method for non-diagnostic and indeterminate nodules on US. However, the rate of non-diagnostic and indeterminate FNA remains high at around $30 \%$. Thus, these patients undergo surgery, but fewer 
than $20 \%$ of surgically removed nodules are malignant $(11,12)$. Therefore, one of the key issues for PTMC patients is detecting new indices and improving the accuracy of diagnosis.

Although the prognosis of PTMC is good, there is still a risk of recurrence and metastasis, including distant metastasis. Currently, it has been recognized that recurrences are related to metastatic lymph nodules (MLNs), extrathyroidal extension (ETE) and multifocal lesions; yet, there is still no accurate method to distinguish PTMC patients with a poor prognosis and risk of recurrence from those with an excellent prognosis. Therefore, PTMC is not a uniform category. Generally, for future clinical work, it is crucial to determine the clinical and especially the molecular parameters that define a small group of PTMCs with an aggressive biological behavior.

miRNAs are small noncoding RNAs that negatively regulate gene expression either through inhibition of mRNA translation or by promoting mRNA degradation. There is also evidence that miRNAs are involved in central biological processes in cancers, including development, organogenesis, tissue differentiation, the cell cycle and metabolism (13-15). Several miRNAs (miR-222, miR-221, miR-146b and miR-21) have been reported to be consistently deregulated in PTC and have been demonstrated to distinguish benign from malignant nodules and have a reasonable diagnostic accuracy in cell lines, FNA and tumor tissue specimens (16-19) To date, there are no reports that have addressed the possibility of evaluating circulating miR-222, miR-221, miR-146b and miR-21 levels in patients with PTMC. Therefore, the objective of this study was to analyze serum miRNA expression before and after surgery in PTMC and to determine their relationship with clinicopathologic factors to elucidate whether the abnormal expression of specific miRNAs correlates with the diagnosis and prognosis of PTMC. In addition, we aimed to elucidate whether there were differences in the expression of miRNAs between PTC and PTMC groups. We also evaluated the preoperative US of these patients with PTMC and compared miRNAs with US with regard to their sensitivity and specificity of the diagnosis of PTMC before surgery. In addition, we also analyzed the combination of miRNAs and US for their diagnostic value for PTMC before surgery and elucidated whether their use could improve the accuracy of diagnosis.

\section{Materials and methods}

This study was granted ethical approval by the Institutional Review Board of Harbin Medical University. Written informed consent was obtained from all participants involved in the study. The reference code for the ethical approval was no. HMUIRB20150020.

Patients. A total of 58 patients with PTMC, 47 patients with PTC with diameters $>1 \mathrm{~cm}, 35$ patients with BNT and 40 controls were enrolled. All patients were recruited at the Department of Thyroid Surgery of the Second Affiliated Hospital of Harbin University (Heilongjiang, China) between September 2013 and December 2016. Additional inclusion criteria were patients with BTN who had single or multiple nodules, patients with PTMC and patients with PTC who were undergoing a thyroidectomy and a final diagnosis was based on the pathological results by two experienced pathologists at the Department of Pathology and at the Department of Thyroid Surgery of the
Second Affiliated Hospital of Harbin University. In addition, 40 control subjects were enrolled from the Physical Examination Center of the Second Affiliated Hospital of Harbin University (Heilongjiang, China) between September 2013 and December 2016. The control subjects were age- and sex-matched volunteers without a current or previous history of any other types of cancer and were confirmed to not have thyroid disease based on a neck US and thyroid hormone measurements.

Preoperative US of patients and controls. All of the controls and patients, including those with PTMC, PTC and BTN had undergone preoperative thyroid US, followed by thyroidectomy and histopathology examination. US procedures were performed prospectively by two ultrasonic physicians with 3-5 years of experience and specialization in thyroid US. Thyroid US was performed with an 8-15 MHz linear-array transducer (HI VISION 500, Japan). The following features of the lesions, using criteria obtained from published reports (20-22), were assessed: Size of the tumor, lesion number, marked hypoechogenicity location, extrathyroidal extension (ETE), lesion echogenicity, cystic degeneration microcalcification, well-defined or ill-defined boundary and a halo sign, The results of US were scored by achieved agreement between two radiologists.

We calculated the probability of malignant nodules using two malignant risk systems including web-based TIRADS (www. gap.kr/thyroidnodule.php) and K-TIRADS, and American Thyroid Association (ATA) guidelines $(23,24)$. Suspicious lesions mainly included those with findings of a score of $\geq 8$ with the web-based TIRADS, high suspicion nodules with K-TIRADS, and high suspicion with the ATA guidelines $(23,24)$.

Samples and RNA extraction. Venous blood samples were collected in vacuum-sealed blood collection tubes from all control subjects and from patients with PTMC and BTN on the day of surgery. The first $1 \mathrm{ml}$ of samples was discarded to reduced possible contamination with miRNA from the dermal plug from the venous puncture. Within $1 \mathrm{~h}$ of collection, the samples were centrifuged at $1,900 \times \mathrm{g}$ for $15 \mathrm{~min}$ at $4^{\circ} \mathrm{C}$. The supernatant was carefully transferred into an RNase-free tube and centrifuged at $12,000 \mathrm{x} \mathrm{g}$ for $10 \mathrm{~min}$ at $4^{\circ} \mathrm{C}$ to remove additional cellular debris and to minimize the contamination of the cell-free nucleic acid by DNA and RNA derived from damaged blood cells. The serum samples were stored at $-80^{\circ} \mathrm{C}$ until RNA extraction.

Total RNA was isolated from $200 \mu \mathrm{l}$ of serum according to the manufacturer's protocol using a miRNeasy serum/plasma kit (Qiagen GmbH, Hilden, Germany). The concentrations of all RNA samples were quantified using a NanoDrop 1000 spectrophotometer (NanoDrop Technologies; Thermo Fisher Scientific, Wilmington, DE, USA). The concentrations of RNA extracted from serum ranged between 14.3 and $26.8 \mathrm{ng} / \mathrm{ml}$.

Selection of miRNAs. The miRNA candidates to be tested were selected based on the following process. Firstly, miRNAs that were enriched in normal thyroid tissues and significantly unregulated in PTC compared with normal thyroid tissues and BTN were selected (25-29). Secondly, we selected miRNAs reported as being upregulated in tumor tissue to determine whether their expression was also elevated in serum derived from patients with PTMC. Finally, miRNAs that were significantly associated with 

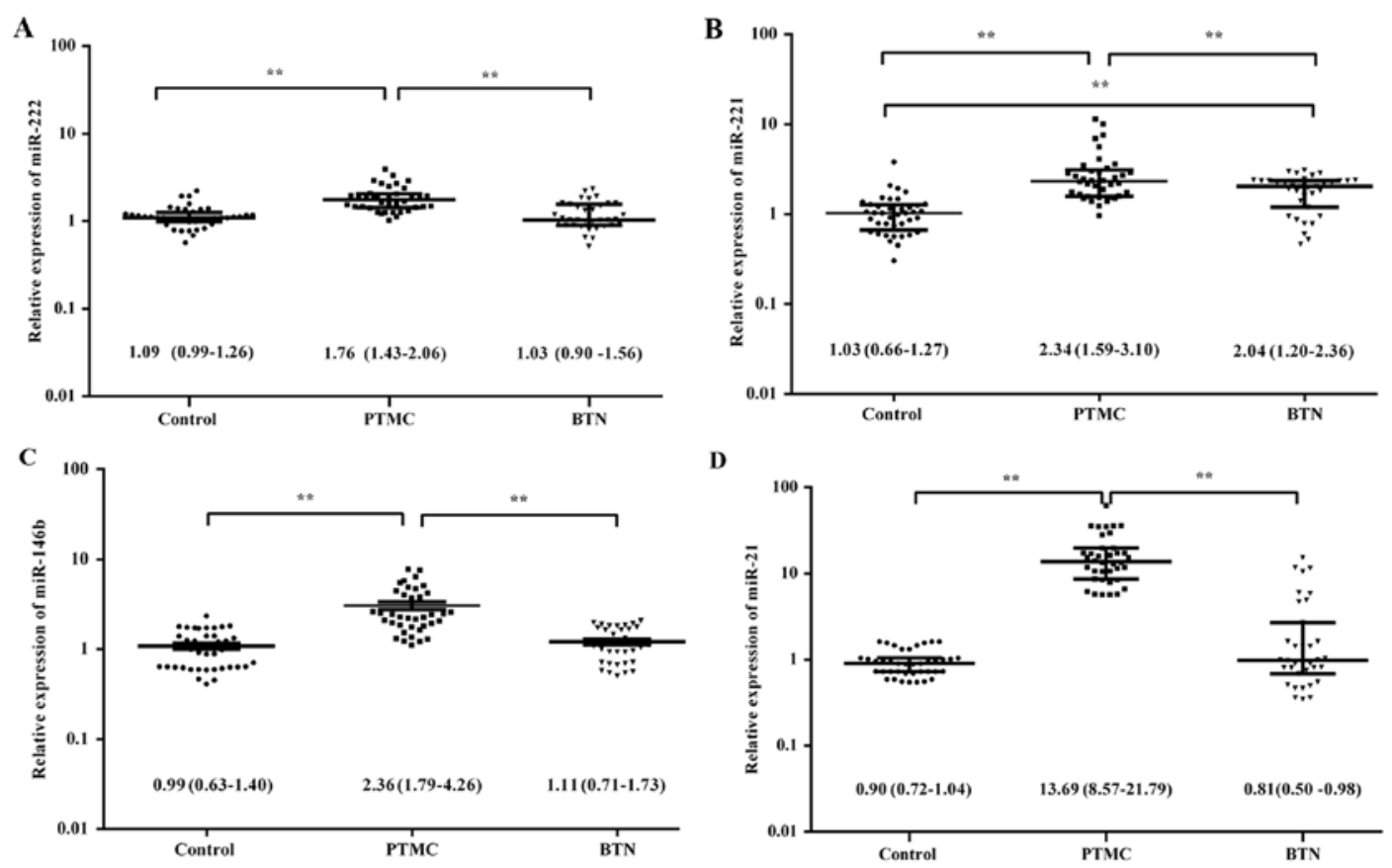

Figure 1. Diagrams of the Mann-Whitney U test results, showing that the relative expression levels of miR-222 (A), miR-221 (B), miR-146b (C) and miR-21 (D) in the PTMC group $(n=58)$ were significantly higher than level in the control $\left(n=40,{ }^{* *} \mathrm{P}<0.01\right)$ and $\mathrm{BTN}\left(\mathrm{n}=35,{ }^{* *} \mathrm{P}<0.01\right)$ groups. The relative expression of miRNAs is presented as the median and interquartile range $2^{-\Delta \Delta C t}$. PTMC, papillary thyroid microcarcinoma; BTN, benign thyroid nodules.

a poor prognosis of PTC were selected (25-32). Based on this selection procedure, 4 miRNAs (miR-222, miR-221, miR-146b and miR-21) were selected as candidate targets for the serum miRNA assay, and we evaluated whether these miRNAs were associated with the diagnosis and prognosis of PTMC.

$q R T-P C R$ analysis of miRNAs. First-strand cDNA synthesis of miRNA was performed using a miRcute miRNA First-Strand cDNA synthesis kit (Tiangen Biotech Co. Ltd., Beijing, China) according to the manufacturer's protocol. Reverse transcription was conducted on a GeneAmp PCR System 9700 (Applied Biosystems; Thermo Fisher Scientific, Inc., Waltham, MA, USA). Briefly, $5 \mu$ of total RNA was extracted from plasma, polyadenylated by poly(A) polymerase and reverse transcribed into cDNA according to the manufacturer's protocol. RT-qPCR was performed in duplicate using the SYBR Green PCR Master Mix (miRcute miRNA qPCR detection kit; Tiangen Biotech Co., Ltd.) with the Stratagene Mx3000PTM real-time PCR system (Applied Biosystems; Thermo Fisher Scientific, Inc.). miRNA-specific primer sequences were designed based on the miRBase database by Primer Premier 5.0 and are presented in Table I.

Some studies have reported that miR-16 has been used as an endogenous reference for serum and plasma miRNA examination, thus miR-16 was selected as an endogenous control in this study (33-35). The relative expression was obtained using the comparative cycle threshold $(\mathrm{Ct})$ method $\left(2^{-\Delta \Delta C t}\right)$. The fold-change in the expression of each miRNA was determined by comparing the mean $2^{-\Delta \Delta \mathrm{Ct}}$ values of the PTC and BTN groups to the mean $2^{-\Delta \Delta \mathrm{Ct}}$ value of the control group (36).

Statistical analysis. Statistical analysis was performed using SPSS version 17.0 (SPSS, Inc., Chicago, IL, USA). The Mann-Whitney U test, Kruskal-Wallis H test and Scheffe's
Table I. miRNA-specific forward primer sequences.

\begin{tabular}{lc}
\hline Gene name & \multicolumn{1}{c}{ Primer sequence } \\
\hline miR-222 & 5'-GGGCTCAGTAGCCAGTGTAGATCC-3' \\
miR-221 & 5'-GGCGACCTGGCATACAATGTAGAT-3' \\
miR-146b & 5'-GGCTGAGAACTGAATTCCATAGGC-3' \\
miR-21 & 5'-CAACACCAGUCGAUGGGCUGU-3' \\
miR-16 & 5'-GCTAGCAGCACGTAAATATTGGCG-3' \\
\hline
\end{tabular}

Post Hoc Multiple Comparisons test were used to determine the significance of the different levels of miRNA expression. Fisher's exact test was used to measure the characteristics in the PTMC and PTC groups. ROC curves were used to analyze the diagnostic utility of differentially expressed miRNAs. The optimal cut-off point was selected as the value with the maximal sum of sensitivity and specificity. A logistic regression model was used to determine the predicated probability of the combination of miRNAs and US. The levels of miRNA in each group were defined by the median and interquartile range (IQR). All P-values were two-sided, and $\mathrm{P}<0.05$ was considered to indicate a statistically significant difference.

\section{Results}

Serum miRNA profiling in PTMC, BTN and control groups. We used qRT-PCR to measure the expression levels of serum miR-222, miR-221, miR-146b and miR-21 in patients with PTMC, BTN and the control subjects. The relative expression of miR-222, miR-221, miR-146b and miR-21 was significantly higher in patients with PTMC compared with BTN or in the control subjects $(\mathrm{P}<0.001$ and $\mathrm{P}<0.001$, respectively; Fig. 1). 
A

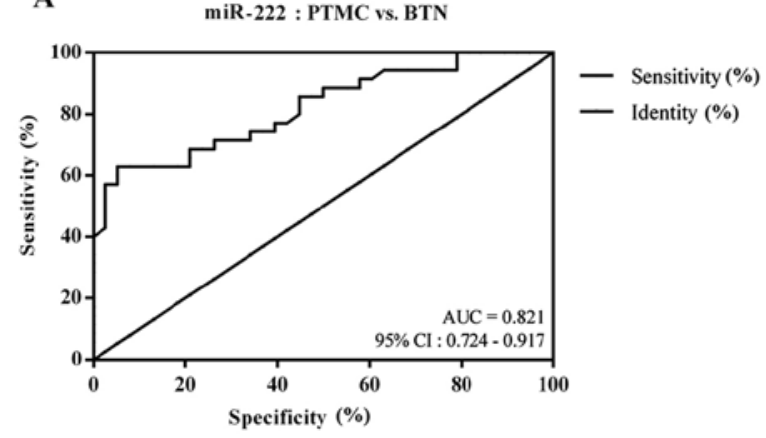

C

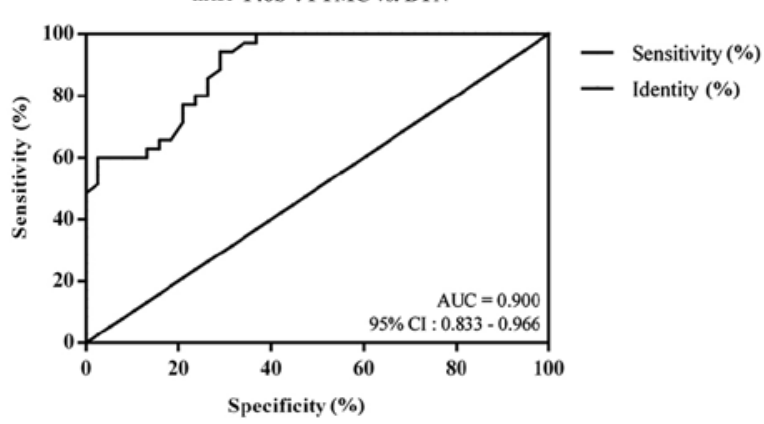

$\mathbf{E}$
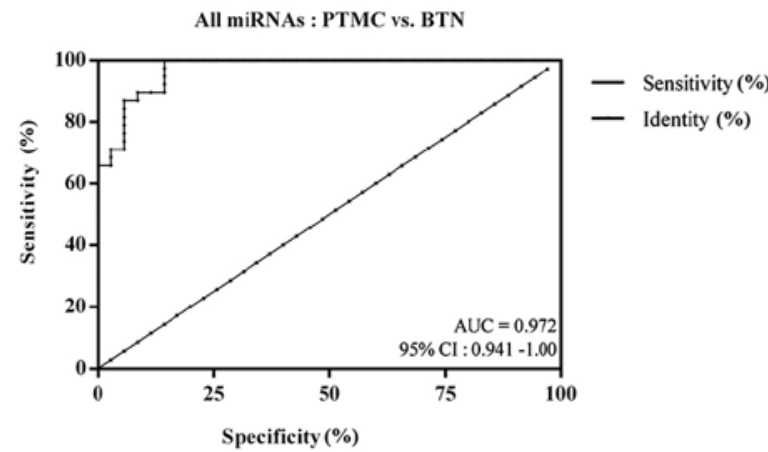

B

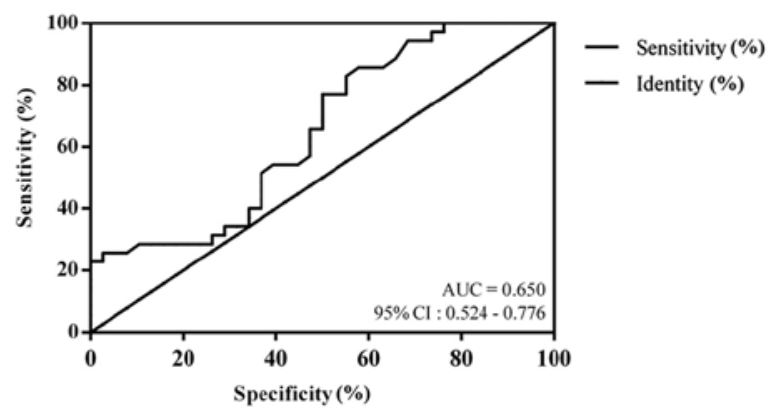

D

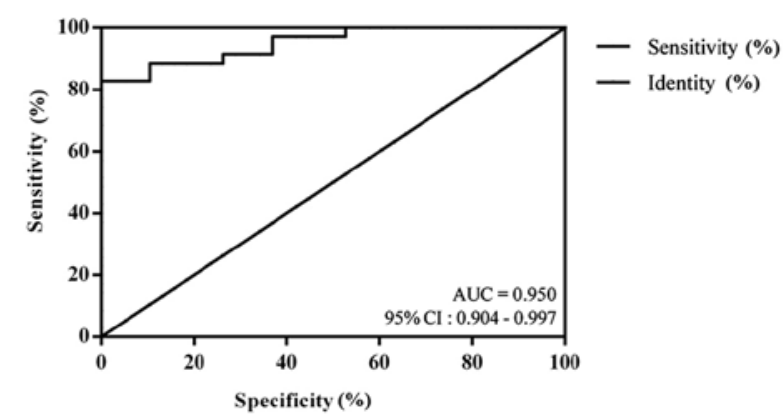

$\mathbf{F}$

All miRNAs and miR-222, miR-221, miR-146b, miR-21: PTMC vs. BTN

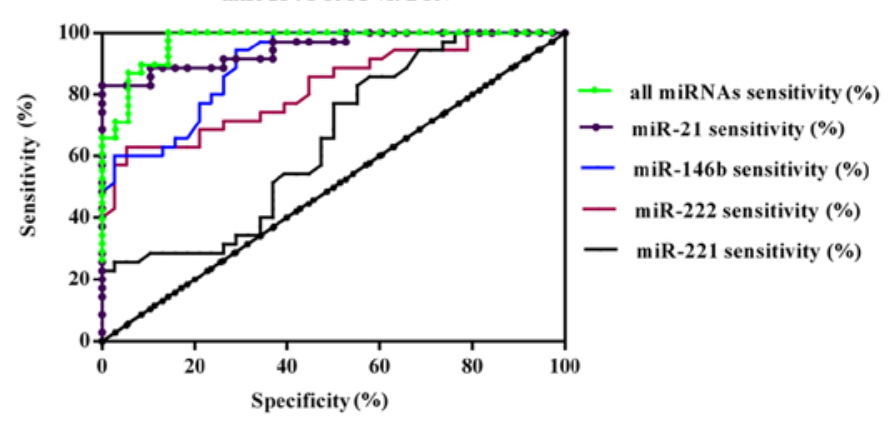

Figure 2. Diagnostic value of miRNAs in discriminating PTMC from BTN. ROC curves were used to distinguish among groups. (A) Serum miR-222 in PTMC vs. BTN. (B) Serum miR-221 in PTMC vs. BTN. (C) Serum miR-146b in PTMC vs. BTN. (D) Serum miR-21 in PTMC vs. BTN. (E) All four miRNAs (miR-222, miR-221, miR-146b and miR-21) in PTMC vs. BTN. (F) All four miRNAs and miR-222, miR-221, miR-146b and miR-21 in PTMC vs. BTN. PTMC, papillary thyroid carcinoma; BTN, benign thyroid nodules; ROC, receiver operating characteristic; AUC, area under the curve.

The fold-changes were 1.61, 2.26, 2.38 and 15.21, respectively, compared with the controls.

We performed ROC curve analysis of the predictive values of miRNAs for preoperative diagnosis in PTMC and BTN. The AUC of miR-222 was 0.821 (95\% CI, 0.724-0.917, Fig. 2) with $60.53 \%$ sensitivity and $92.50 \%$ specificity, at a cutoff value of 1.59 . The AUC of miR-221 was $0.650(95 \%$ CI, 0.524-0.776, Fig. 2) with $77.14 \%$ sensitivity and $50 \%$ specificity, at a cut-off value of 2.37. The AUC of miR-146b was 0.900 (95\% CI, 0.833-0.966, Fig. 2) with $77.14 \%$ sensitivity and $78.95 \%$ specificity, at a cutoff value of 1.74 . The AUC of miR-21 was 0.95 (95\% CI, 0.904-0.997, Fig. 2) with $88.57 \%$ sensitivity and $89.47 \%$ specificity, at a cut-off value of 6.06. Also, we analyzed the ROC curve of a combination of miR-222, miR-221, miR-146b and miR-21. The AUC of all 4 miRNAs was 0.972 (95\% CI, 0.941-1.00, Fig. 2) with $86.84 \%$ sensitivity and $94.29 \%$ specificity, an improved sensitivity and specificity of diagnosis compared with each single miRNA.
Table II shows the sensitivity, specificity and accuracy of diagnosis with US, miRNAs and the combination of US and miRNAs in the detection of benign or malignant nodules in the thyroid. miR-222 had high specificity $(\mathrm{P}=0.003)$ and low sensitivity (no significance, $\mathrm{P}=0.375$ ) and had a high false-negative rate and low false-positive rate compared with US. US combined with miR-222 had higher sensitivity $(\mathrm{P}<0.001)$ and specificity (no significance, $\mathrm{P}=0.377$ ), and a low false-positive rate and false-negative rate compared with single US. US had a low sensitivity (no significance, $\mathrm{P}=0.205$ ) and high specificity $(\mathrm{P}<0.001)$ and had a low false-positive rate and high false-negative rate compared with miR-221. US combined with miR-221 had high sensitivity and specificity (no significance, $\mathrm{P}=0.731$ and $\mathrm{P}=0.109$, respectively) and a low false-positive rate and false-negative rate compared with single US. US had a high sensitivity and low specificity (no significance, $\mathrm{P}=0.097$ and $\mathrm{P}=0.552$, respectively), as well as a high false-positive rate and low false-negative rate compared with 
Table II. Comparison of US and miRNAs in the diagnostic method of PTMC.

\begin{tabular}{lccccc}
\hline $\begin{array}{l}\text { Preoperative method } \\
\text { of thyroid nodules }\end{array}$ & $\begin{array}{c}\text { Specificity } \\
\%\end{array}$ & $\begin{array}{c}\text { False-positive rate } \\
\%\end{array}$ & P-value & $\begin{array}{c}\text { Sensitivity } \\
\%\end{array}$ & $\begin{array}{c}\text { False-negative rate } \\
\%\end{array}$ \\
\hline A, Comparison of US and miRNAs & & & & 0.375 \\
\hline US & 77.14 & 22.86 & $\mathbf{0 . 0 0 3}$ & 68.42 & 31.58 \\
miR-222 & 92.5 & 7.5 & & 60.53 & 39.47 \\
US & 77.14 & 22.86 & $\mathbf{4 0 . 0 0 1}$ & 68.42 & 31.57 \\
miR-221 & 50 & 50 & & 77.41 & 22.59 \\
US & 77.14 & 22.86 & 0.097 & 68.42 & 31.57 \\
miR-146b & 86.84 & 13.16 & & 62.86 & 37.14 \\
US & 77.14 & 22.86 & $\mathbf{4 0 . 0 0 1}$ & 68.42 & 31.57 \\
miR-21 & 94.74 & 5.26 & & 82.86 & 17.14 \\
US & 77.14 & 22.86 & $\mathbf{0 . 0 0 1}$ & 68.42 & 31.57 \\
All miRNAs & 94.29 & 5.71 & & 86.84 & $\mathbf{0 . 0 2 1}$ \\
\hline
\end{tabular}

B, Comparison of single US and the combination of miRNAs and US

\begin{tabular}{|c|c|c|c|c|c|c|}
\hline US & 77.14 & 22.86 & 0.377 & 68.42 & 31.57 & $<0.001$ \\
\hline miR-222+US & 82.86 & 17.14 & & 89.47 & 10.53 & \\
\hline US & 77.14 & 22.86 & 0.731 & 68.42 & 31.57 & 0.109 \\
\hline miR-221+US & 80 & 20 & & 78.95 & 21.05 & \\
\hline US & 77.14 & 22.86 & 0.011 & 68.42 & 31.57 & $<0.001$ \\
\hline miR-146b+US & 91.43 & 8.57 & & 89.47 & 10.53 & \\
\hline US & 77.14 & 22.86 & 0.011 & 68.42 & 31.57 & $<0.001$ \\
\hline miR-21+US & 91.43 & 8.57 & & 94.74 & 5.26 & \\
\hline US & 77.14 & 22.86 & 0.048 & 68.42 & 31.57 & $<0.001$ \\
\hline All miRNAs+US & 92.11 & 7.89 & & 91.43 & 8.57 & \\
\hline
\end{tabular}

P-values were calculated using Fisher's exact test; values in bold indicate significant differences. There was no significant difference noted in diagnostic specificity with US and miR-222, miR-21, miR-222 and all miRNAs $(\mathrm{P}=0.003, \mathrm{P}<0.001, \mathrm{P}<0.001$ and $\mathrm{P}=0.001$, respectively). The combination of US with miR-146b, miR-21 and all miRNAs was found to improve the specificity of diagnosis compared with the single US method $(\mathrm{P}=0.011, \mathrm{P}=0.011$ and $\mathrm{P}=0.048$, respectively). There was significant difference noted in diagnostic sensitivity with $\mathrm{US}$ and miR-21 and all miRNAs ( $\mathrm{P}=0.021$ and $\mathrm{P}=0.002$, respectively). The combination of US with miR-222, miR $146 \mathrm{~b}$, miR-21 and all miRNAs was found to improve the sensitivity of diagnosis compared with the single US method $(\mathrm{P}<0.001, \mathrm{P}<0.001, \mathrm{P}<0.001$ and $\mathrm{P}<0.001$, respectively). US, ultrasound; PTMC, papillary thyroid microcarcinoma.

miR-146b. US combined with miR-146b had a high sensitivity and specificity $(\mathrm{P}=0.011$ and $\mathrm{P}<0.001$, respectively) and had a low false-positive rate and false-negative rate compared with single US. US had a low specificity and low sensitivity $(\mathrm{P}=0.021$ and $\mathrm{P}<0.001$, respectively), as well as a high false-positive rate and high false-negative rate compared with miR-21. US combined with miR-21 had a high sensitivity and specificity $(\mathrm{P}=0.011$ and $\mathrm{P}<0.001$, respectively) and a low false-positive rate and false-negative rate compared with single US. US had a low sensitivity and low sensitivity $(\mathrm{P}=0.001$ and $\mathrm{P}=0.002$, respectively), as well as a high false-positive rate and high false-negative rate compared with all miRNAs (combination of miR-222, miR-221, miR-146b and miR-21). US combined with all miRNAs had a high sensitivity and specificity $(\mathrm{P}=0.048$ and $\mathrm{P}<0.001$, respectively) and a low false-positive rate and false-negative rate compared with single US alone.

In addition, we performed ROC curve analysis to predict values of US for preoperative diagnosis of PTMC and BTN.
The results indicated that the use of US had an AUC of 0.728 (95\% CI, 0.609-0.846, Fig. 3) with $77.14 \%$ sensitivity and $65.79 \%$ specificity. We also analyzed miRNAs combined with US and evaluated whether the combination may improve the diagnosis of PTMC. The results indicated that the combination of US and miR-222 had an AUC of 0.866 (95\% CI, $0.807-0.964$, Fig. 3) with sensitivity $82.86 \%$ and specificity $89.47 \%$. The combination of US and miR-221 had an AUC of 0.809 (95\% CI, 0.725-0.893, Fig. 3) with sensitivity $80 \%$ and specificity $78.95 \%$. The combination of US and miR-146b had an AUC of 0.942 (95\% CI, 0.902-0.983, Fig. 3) with sensitivity $91.43 \%$ and specificity $89.47 \%$. The combination of US and miR-21 had an AUC of 0.970 (95\% CI, 0.933-1.0, Fig. 3) with sensitivity $91.43 \%$ and specificity $94.74 \%$. The combination of four miRNAs and US indicated that the combination had an AUC of 0.971 (95\% CI, 0.935-1.00, Fig. 3) with sensitivity $91.43 \%$ and specificity $92.11 \%$ and improved the diagnosis rate compared with US alone (Fig. 3). 
A

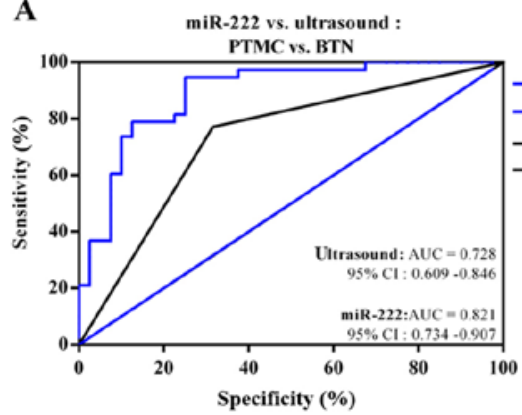

C

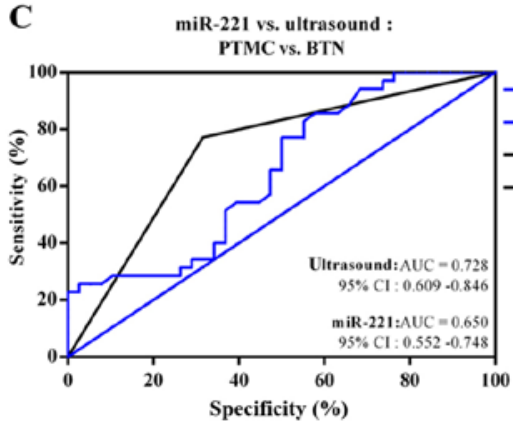

$\mathbf{E}$

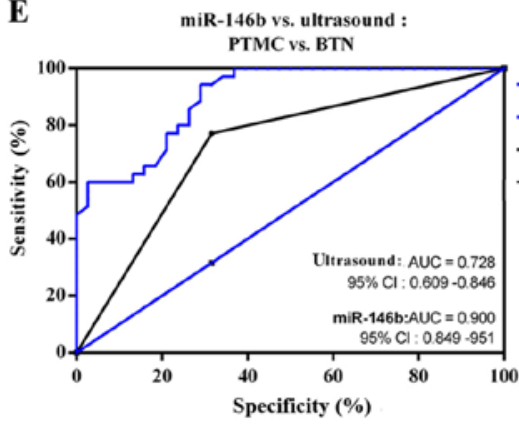

$\mathbf{G}$
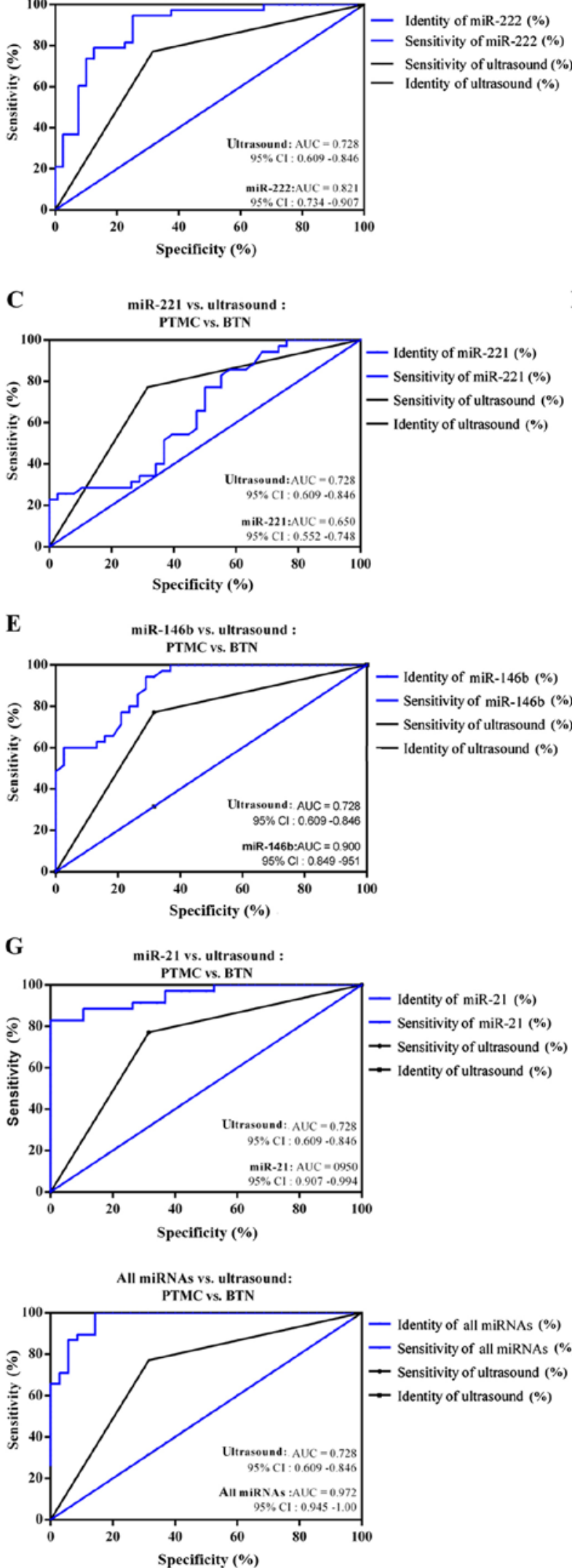

B

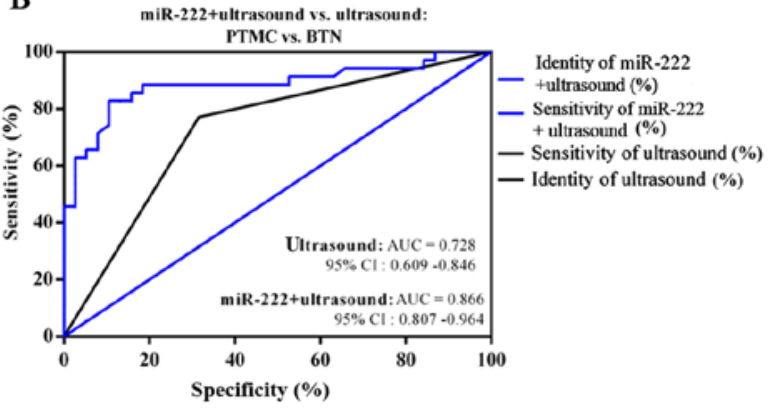

D

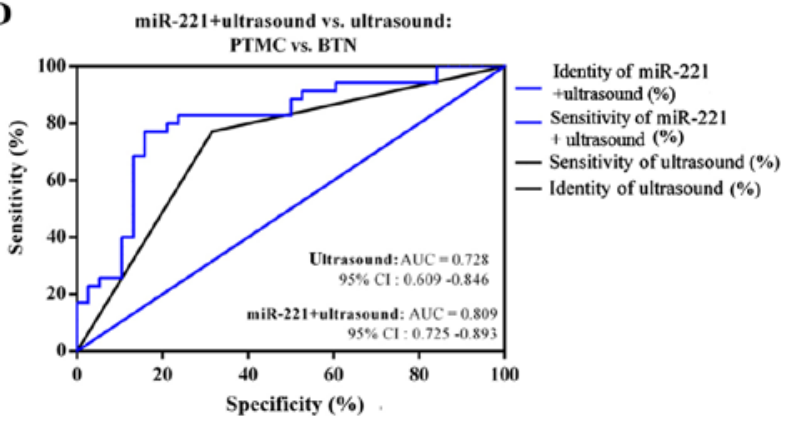

$\mathbf{F}$

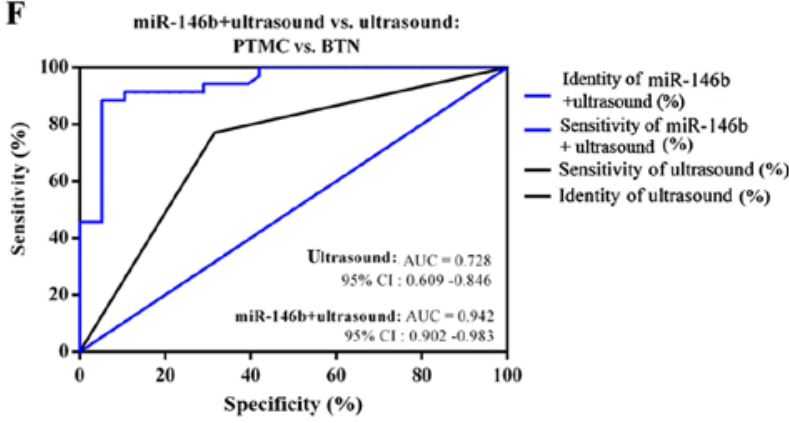

$\mathbf{H}$

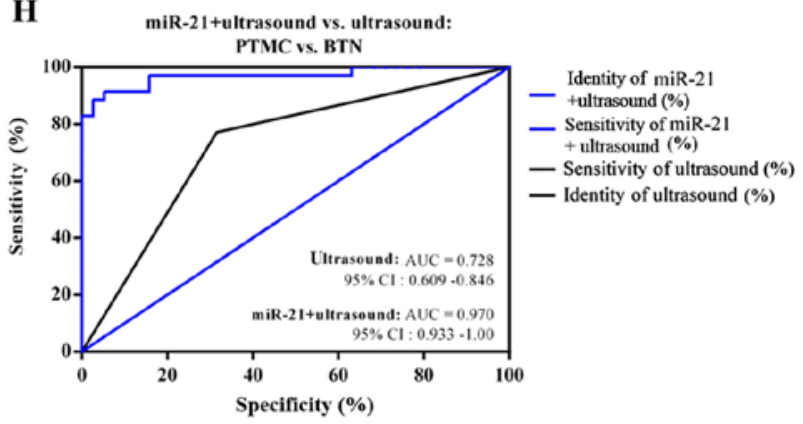

J All miRNAs+ultrasound vs. ultrasound:

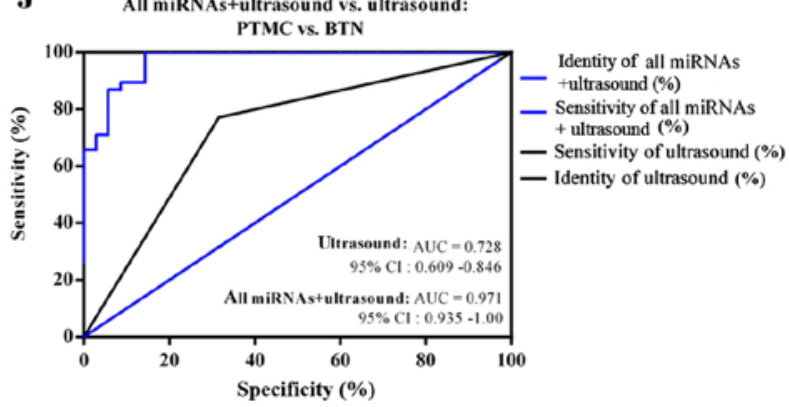

Figure 3. Diagnostic value of miRNAs in discriminating PTMC from and BTN. ROC curves were used to distinguish among groups. (A) Serum miR-222 and US in PTMC vs. BTN. (B) Combination of miR-222 and US compared with single US in PTMC vs. BTN. (C) Serum miR-221 and US in PTMC vs. BTN. (D) The combination of miR-221 and US compared with single US in PTMC vs. BTN. (E) Serum miR-146b and US in PTMC vs. BTN. (F) The combination of miR-146b and US compared with single US in PTMC vs. BTN. (G) Serum miR-21 and US in PTMC vs. BTN. (H) The combination of miR-21 and US compared with single US in PTMC vs. BTN. (I) All four miRNAs (miR-222, miR-221, miR-146b and miR-21) and US in PTMC vs. BTN. (J) The combination of all four miRNAs (miR-222, miR-221, miR-146b and miR-21) and US compared with single US in PTMC vs. BTN. PTMC, papillary thyroid carcinoma; BTN, benign thyroid nodules; ROC, receiver operating characteristic; AUC, area under the curve. 
Table III. Characteristics of the patients with PTMC and PTC.

\begin{tabular}{|c|c|c|c|}
\hline Characteristics & $\begin{array}{c}\text { PTMC }(n=58) \\
n(\%)\end{array}$ & $\begin{array}{c}\text { PTC }(\mathrm{n}=47) \\
\mathrm{n}(\%)\end{array}$ & $\mathrm{P}$-value \\
\hline \multicolumn{4}{|c|}{ Sex (male/female, \%) } \\
\hline Male, n (\%) & $20(34.5)$ & $18(38.3)$ & \multirow[t]{2}{*}{0.420} \\
\hline Female, n (\%) & $38(65.5)$ & $29(61.7)$ & \\
\hline \multicolumn{4}{|c|}{ Age (years), n (\%) } \\
\hline$<45$ & $26(44.8)$ & $31(66.0)$ & \multirow[t]{2}{*}{0.024} \\
\hline$\geq 45$ & $32(55.2)$ & $16(34.0)$ & \\
\hline \multicolumn{4}{|c|}{ Tumor location, n (\%) } \\
\hline Unilateral & $32(44.8)$ & $24(51.1)$ & \multirow[t]{2}{*}{0.698} \\
\hline Bilateral & $26(55.2)$ & $23(48.9)$ & \\
\hline \multicolumn{4}{|c|}{ Multicentricity, n (\%) } \\
\hline Yes & $22(37.9)$ & $12(25.5)$ & \multirow[t]{2}{*}{0.211} \\
\hline No & $36(62.1)$ & $35(74.5)$ & \\
\hline \multicolumn{4}{|c|}{ Extrathyroidal extension, $\mathrm{n}(\%)$} \\
\hline Yes & $10(17.2)$ & $8(17.0)$ & \multirow[t]{2}{*}{0.346} \\
\hline No & $48(82.8)$ & $39(83.0)$ & \\
\hline \multicolumn{4}{|c|}{ Metastatic lymph node, n (\%) } \\
\hline Yes & $30(51.7)$ & $31(66.0)$ & \multirow[t]{2}{*}{0.167} \\
\hline No & $28(48.3)$ & $16(34.0)$ & \\
\hline \multicolumn{4}{|c|}{ TNM stage (AJCC), n (\%) } \\
\hline $\mathrm{I} / \mathrm{II}$ & $37(63.8)$ & $28(59.6)$ & \multirow[t]{2}{*}{0.690} \\
\hline III/IV & $21(36.2)$ & $19(40.4)$ & \\
\hline \multicolumn{4}{|l|}{ AMES, n (\%) } \\
\hline Low risk & $51(87.9)$ & $42(89.4)$ & \multirow[t]{2}{*}{0.535} \\
\hline High risk & $7(12.1)$ & $5(10.6)$ & \\
\hline \multicolumn{4}{|c|}{ miRNAs, median (interquartile range) } \\
\hline miR-222 & $1.83(0.99-1.26)$ & $2.69(1.43-2.15)$ & 0.002 \\
\hline $\operatorname{miR}-221$ & $2.34(1.59-3.10)$ & $3.23(1.79-5.39)$ & 0.121 \\
\hline $\operatorname{miR}-146 b$ & $2.55(1.39-3.97)$ & $2.36(1.79-4.26)$ & 0.891 \\
\hline $\operatorname{miR}-21$ & $13.69(8.57-21.79)$ & $34.06(21.71-47.18)$ & $<0.001$ \\
\hline
\end{tabular}

P-values were calculated using Fisher's exact test and Mann-Whitney U test results; values in bold indicate significant differences. Table representation of Mann-Whitney $U$ test results, showing that the relative expression of miR-222, miR- 221, miR-146 and miR-21 is presented as the median and interquartile range $\left(2^{-\Delta \Delta C q}\right)$. TNM stage was assessed according to the AJCC staging systems; AMES is a risk stratification including age, metastasis, extent and size. PTC, papillary thyroid carcinoma; PTMC, papillary thyroid microcarcinoma; TNM, tumor node metastasis; AJCC, American Joint Committee on Cancer.

Correlation of miRNA expression in patients with PTMC and with PTC. A total of 105 newly diagnosed PTC patients, of which 58 were PTMC and 47 were non-PTMC with diameters $>1 \mathrm{~cm}$ were investigated. There was a significant difference in terms of age between the two groups $(\mathrm{P}=0.024)$ and no significant differences for other clinical features including sex, tumor location, multicentricity, ETE, MLN, TNM staging or risk stratification ( $\mathrm{P}>0.05$, Table III). Both groups showed a female predominance. The results indicated that serum miR-222 and miR-21 levels were significantly higher in patients with PTC compared with PTMC ( $\mathrm{P}=0.002$ and $\mathrm{P}<0.001$, respectively, Table III).

Correlation of miRNAs and clinicopathological characteristics of PTMC. We assessed the relationship between
miRNA profiles and clinicopathological characteristics. The expression levels of the four miRNAs were not significantly different in regards to sex and age $(\mathrm{P}>0.05)$. The results indicated that serum miR-222, miR-146b and miR-21 levels were significantly higher in patients with bilateral lesions $(\mathrm{P}=0.005$, $\mathrm{P}=0.001$ and $\mathrm{P}=0.015$, respectively, Table IV); patients with multifocal lesions $(\mathrm{P}=0.002, \mathrm{P}=0.005$ and $\mathrm{P}=0.005$, respectively, Table IV); and patients with metastatic lymph nodes ( $\mathrm{P}=0.014, \mathrm{P}=0.031$ and $\mathrm{P}=0.029$, respectively; Table IV). The present results also indicated that serum miR-222 and miR-21 overexpression was clearly associated with ETE $(\mathrm{P}=0.026$ and $\mathrm{P}=0.021$, respectively; Table IV) and patients with a high risk $(\mathrm{P}=0.006$ and $\mathrm{P}=0.026$, respectively; Table IV). The present results also indicated that serum miR-222, miR-221 and 


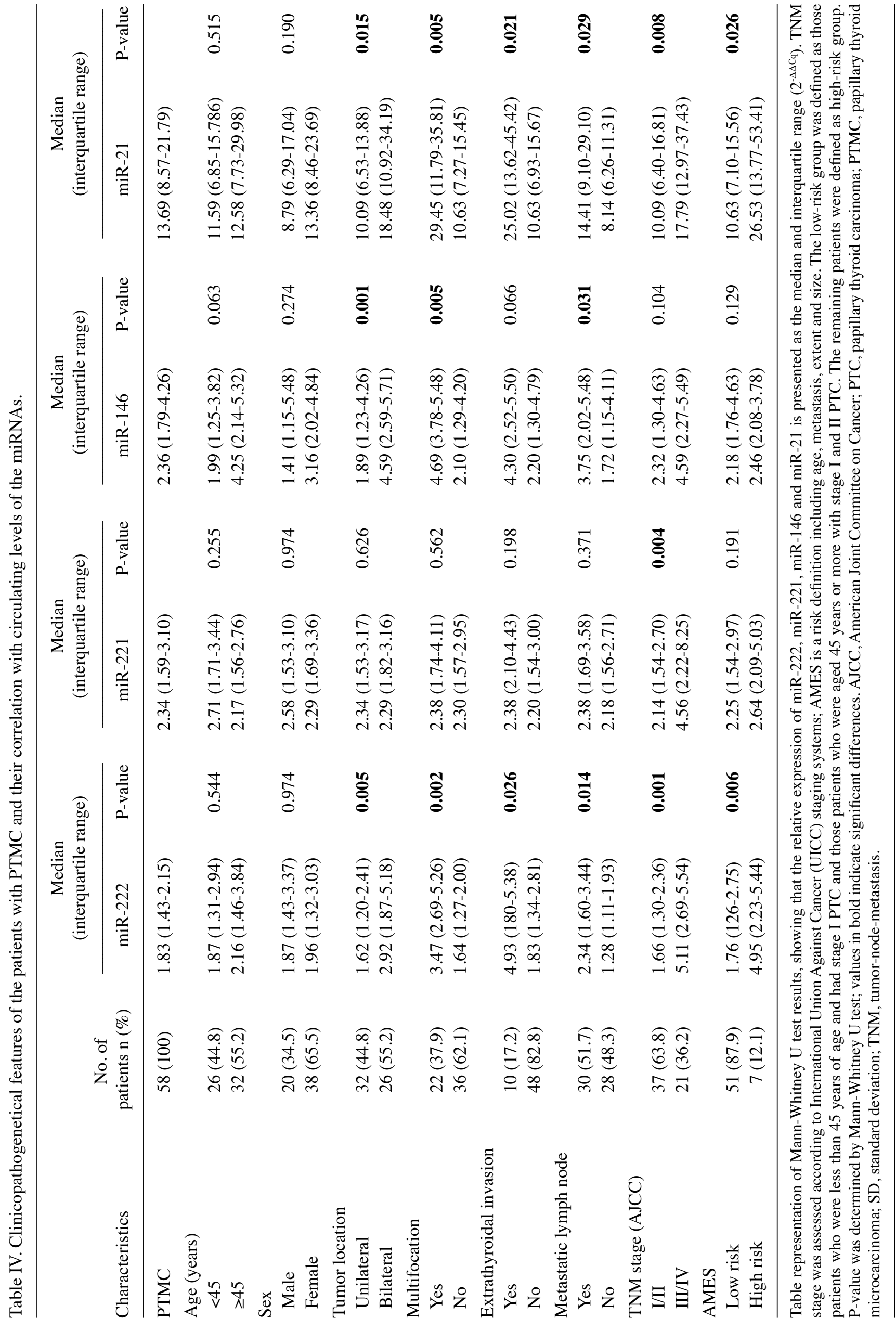


A

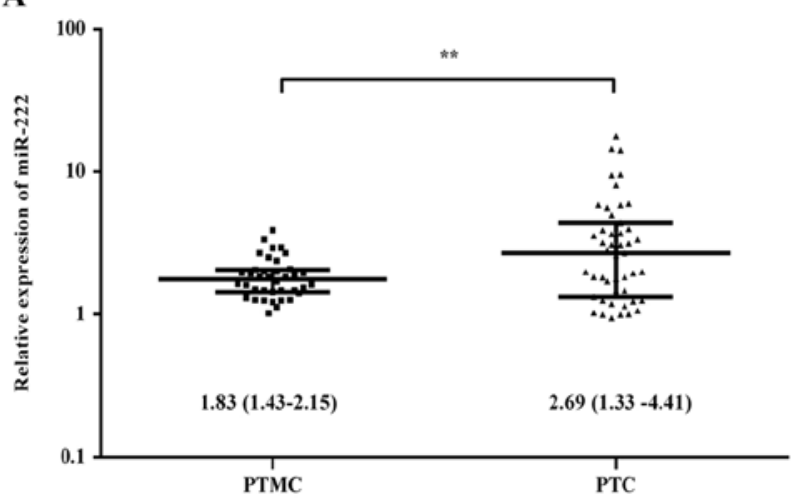

B

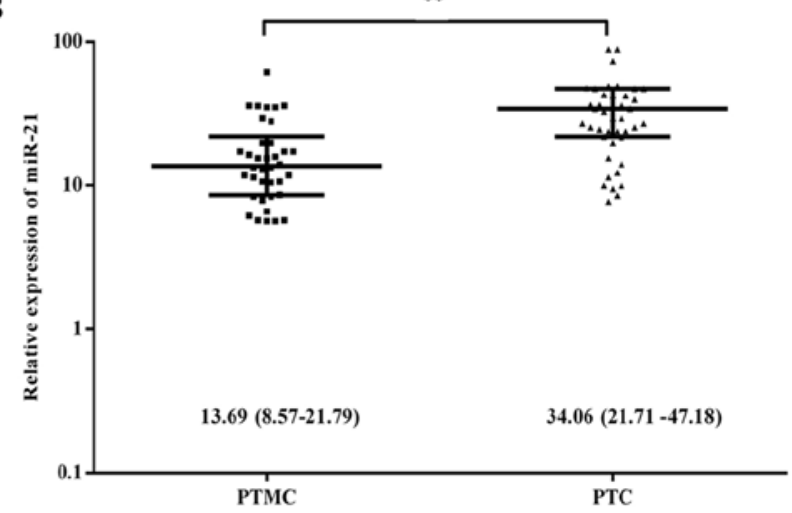

Figure 4. Diagram of the Mann-Whitney U test results, showing that the relative expression levels of miR-222 (A) and miR-21 (B) in the PTC group (n=47) were significantly higher than levels in PTMC $\left(n=58,{ }^{* *} \mathrm{P}<0.01\right)$. The relative expression of miRNAs is presented as the median and interquartile range $2^{-\Delta \Delta C q}$. PTMC, papillary thyroid microcarcinoma; PTC, papillary thyroid microcarcinoma.
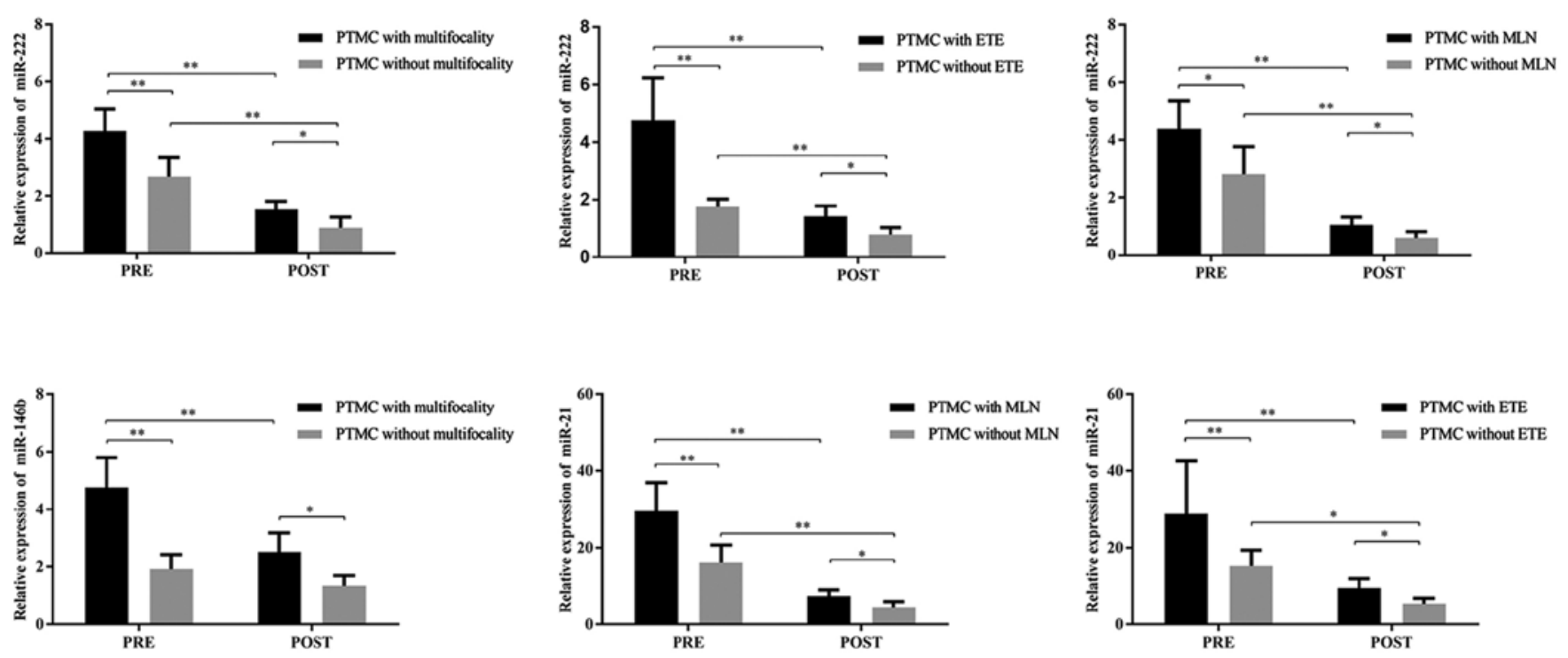

Figure 5. Expression of four miRNAs in patients with PTMC $(n=30)$ before and after surgery in the various groups divided into two groups according to prognostic factors of PTMC. The levels of miR-222, miR-146b and miR-21 were significantly higher in patients with poor prognoses before and after surgery $\left({ }^{* *} \mathrm{P}<0.01,{ }^{*} \mathrm{P}<0.05\right)$. The relative expression of miRNAs is presented as the median and interquartile range $2^{-\Delta \Delta C q}$. All P-values were determined using the Kruskal-Wallis H test and Scheffe's Post Hoc multiple comparisons test. PTMC, papillary thyroid microcarcinoma; PRE, preoperative; POST, postoperative, miR, microRNA; ETE, extrathyroidal extension; MLN, metastatic lymph nodules.

miR-21 overexpression was clearly associated with advanced TNM stage $(\mathrm{P}=0.001, \mathrm{P}=0.004$ and $\mathrm{P}=0.008$, respectively; Table IV).

Association of miRNA expression and poor prognostic factors before and after surgery in PTMC. We also measured the miRNA expression levels one month after surgery and compared them with preoperative expression in serum from patients with PTMC. The results suggested that the serum expression of miR-222, miR-221, miR-146b and miR-21 decreased significantly after surgery compared with before surgery in 30 patients with $\mathrm{PTMC}(\mathrm{P}<0.001, \mathrm{P}=0.002, \mathrm{P}=0.013$ and $\mathrm{P}<0.001$, respectively, Fig. 4).

Simultaneously, we analyzed the expression levels of the four miRNAs in various groups according to the prognosis of PTMC patients before and after surgery. The results demonstrated that the miR-222 expression levels were significantly higher in patients with multifocal lesions, ETE and MLN before $(\mathrm{P}<0.001, \mathrm{P}<0.001$ and $\mathrm{P}=0.012$, respectively) and after $(\mathrm{P}=0.032, \mathrm{P}=0.031$ and $\mathrm{P}=0.014$, respectively) surgery (Fig. 5). miR-146b expression was significantly higher in patients with multifocal lesions before $(\mathrm{P}<0.001)$ and after $(\mathrm{P}=0.016)$ surgery (Fig. 5). miR-21 expression was significantly higher in patients with ETE and MLN before $(\mathrm{P}=0.002$ and $\mathrm{P}<0.001$, respectively) and after $(\mathrm{P}=0.027$ and $\mathrm{P}=0.035$, respectively) surgery (Fig. 5). There was no difference in the other groups $(\mathrm{P}>0.05)$.

\section{Discussion}

Ultrasound (US) has attracted considerable research attention in the diagnosis of papillary thyroid microcarcinoma (PTMC) as a non-invasive imaging method that is useful for identifying benign or malignant nodules. However, US has limitations 
associated with small nodules, especially those smaller than $5 \mathrm{~mm}$, and has a low sensitivity and specificity of diagnosis of PTMC. The proportion of non-diagnostic and indeterminate US accounted for 20-30\% in PTMC, especially for nodules smaller than $5 \mathrm{~mm}$ in maximal diameter. Many of these patients repeatedly undergo fine-needle aspiration (FNA) or surgery, but fewer than $20 \%$ are found to be malignant by pathology $(11,37)$. There is no doubt that repeated FNA can increase the cost and psychological burden of patients. In addition, US is not sensitive for the detection of central lymph node metastasis, detecting $<10 \%$ (38). This is mainly due to the location of the nodes as well as interference from the trachea and pulsating vessels. FNA is recommended for thyroid nodules larger than $10 \mathrm{~mm}$, even for those with highly suspicious sonographic features, according to the 2015 ATA guidelines (20). Therefore, US-guided FNA is not widely appropriate to diagnose thyroid nodules, especially for small thyroid nodules or multifocal lesions.

miRNAs can be isolated from serum or plasma, and they can be used to detect many types of cancers (39-41). However, the promising use of miRNAs as biomarkers for PTC has been reported in only a few studies $(28,35,42-45)$. To date, no studies have examined circulating miRNA expression in PTMC patients, and none have attempted to use serum miRNAs to analyze their association with the clinicopathologic features of PTMC. Although a few previous studies have demonstrated that circulating let-7e, miR-222, miR-221, miR-146b, miR-151-5p, miR-190 and miR-95 are overexpressed in PTC compared with benign thyroid nodules and healthy controls and offered a promising method for preoperative diagnosis of PTC, there is controversy and unresolved issues involving these studies $(28,35,42-45)$. Firstly, different expression levels of the target miRNAs were noted in these various studies. These findings could be interpreted as indicating that differential expression of miRNAs is due to different regions and races of patients with PTC. Secondly, the expression patterns of serum miRNAs have not yet been clearly elucidated with patterns of PTMC in the current studies. Thirdly, the correlation between several miRNAs and their link to a poor prognosis remains ambiguous. Finally, a comparative analysis of the sensitivity and specificity of diagnosis with US and miRNAs has not yet been performed for distinguishing PTMC from benign thyroid lesion (BTN).

In the present study, we performed an initial analysis of the expression of circulating miRNAs in patients with PTMC or BTN and in control subjects and estimated their diagnostic usefulness for distinguishing between benign and malignant lesions. The expression of tissue-derived miR-222, miR-221, miR-146b and miR-21 was increased in PTC compared with BTN, and their overexpression in tissue was associated with a poor prognosis based on the results of the published literature. Therefore, we selected 4 miRNAs, including miR-222, miR-221, miR-146b and miR-21, as target miRNAs. Our results indicated that serum miR-222, miR-221, miR-146b and miR-21 are overexpressed in patients with PTMC compared with BTN and control subjects. In addition, our results indicated that the relative expression levels of miR-222 and miR-21 in the PTC group are significantly higher than levels in PTMC. For miR-221 and miR-146b, there was no significant difference in expression between the PTMC and PTC groups. The difference in expression is currently unexplained. Kim et al analyzed the gene expression profiles of PTMC and PTC. Their results indicated that for gene expression profiles of PTMCs and PTCs, no significant difference was found. Therefore, they proposed that PTMC should not be considered to be a simple occult indolent thyroid cancer, but as an earlier stage of the disease that eventually evolves into PTC, since the gene expression profiles of PTMCs were not different from those of PTCs (46).

We also used ROC curves to verify their value in the diagnosis of PTMC compared with BTN before surgery. The ROC of miR-222, miR-146b and miR-21 had a higher sensitivity and specificity for diagnosis compared with US in separating the PTMC from the BTN groups. In addition, the ROC of the combination of miRNAs and US had higher sensitivity and specificity for diagnosis compared with single US or miRNAs in separating the PTMC from BTN groups. Therefore, our results indicated that the combination of US and serum miR-222, miR-221, miR-146b and miR-21 may serve as a preoperative invasive biomarker of diagnosis and differential diagnosis. Furthermore, the levels of the four miRNAs were significantly decreased one month after surgery compared with before surgery in serum from patients with PTMC. This finding could suggest that circulating miRNAs are closely associated with the tumorigenesis of PTMC.

Although increasing numbers of studies have demonstrated that circulating miRNAs have been examined in bodily fluids including plasma, urine, peripheral blood and saliva, they were found to be quite stable and reproducible in serum. However, the pathogenesis involved in the release of miRNAs from tumor tissue into the circulation remains unclear. There was some speculation that circulating miRNAs may be a product of tumor cell death and lysis, or they may be released from tumor-derived macrovesicles or exosomes, or they may be a product of a cancer-associated immune response $(47,48)$.

Although PTMC generally has an excellent prognosis, the long-term rate of recurrence of PTMC has been reported to be as high as $10 \%$ (49). A meta-analysis including more than 4,000 patients with PTMC indicated that $28 \%$ of patients had metastatic lymph nodes, $3.3 \%$ of patients progressed to recurrence, and $0.6 \%$ of tumors had a distant metastasis (50). Therefore, it is important to identify predictive factors associated with a poor prognosis that may help physicians adopt tailored appropriate treatment strategies for patients.

Currently, genetic biomarkers are used to evaluate aggressive behaviors in PTMC. Several reports have suggested a correlation between BRAF mutations and advanced TNM stage, extrathyroidal extension (ETE), metastatic lymph nodules and multifocal lesions (51-53). However, BRAF mutations have been found in 24-63\% of PTMC cases and there is no large set of data reporting an association between BRAF and aggressive behaviors of PTMC (54-57). Currently, there are no reliable clinical features including molecular markers, that can differentiate PTMC in patients who develop progressive disease from indolent PTMC (58-61). Further studies are needed not only in regards to the natural history of PTMC but also concerning the identification of markers indicating progressiveness or indolence in PTMC.

In this study, we assessed the relationship between miRNA profiles and clinicopathological characteristics. The 
results indicated that serum miR-222, miR-146b and miR-21 levels were significantly associated with factors indicating a poor prognosis, including those with bilateral and multifocal lesions, metastatic lymph nodes and high-risk groups. Previous studies have documented that miR-222, miR-221, miR-146b and miR-21 are significantly overexpressed in tumor specimens from aggressive and recurrent PTC in tumor specimens $(29,31,62-64)$. Chou et al demonstrated that the expression levels of miR-221, miR-222, and miR-146b were significantly associated with ETE and that the expression levels of miR-221 and miR-146b were significantly higher in the high-risk PTC group (31).

The miR-146b expression levels in PTCs with BRAF mutations were significantly higher than in those without mutations. However, it is essential to identify the gene targets of these miRNAs (31). Previous studies have already demonstrated that miR-146b is overexpressed in tumor specimens from PTC patients and is associated with a poor prognosis or aggressive behavior, including extrathyroidal extension, advanced stages, BRAF mutations, large tumor size and shorter survival, thus it was regarded as a relevant diagnostic and prognostic marker for PTC. miR-146b miRNA is the product of the miR-146b gene that is located on chromosome 10 at position q24.32. Other studies that have focused on various computational target genes in PTC identified 34 target genes for miR-146b (65). The analysis of their biological activities showed that many target genes were involved in cellular proliferation, differentiation, apoptosis, the cell cycle, and signaling transduction pathways, suggesting a role of this miRNA in the pathogenesis of PTC (65).

In addition, similar to previous reports $(18,45,66-68)$ our results indicated that the expression levels of miR-222 and miR-221 are significantly increased in serum from III/IV stage PTMC cases. A previous study suggested that both miR-222 and miR-221 are clustered on the $\mathrm{X}$ chromosome, and it is likely that they are encoded by a single polycistron, as was previously suggested (69). They are involved in cell proliferation through the inhibition of the cell cycle regulator, p27kip1, in human papillary carcinomas. A study by Mardente et al showed that HMGB1 increased the expression of miR-221 and miR-222 in primary cultures of excised papillary lesions. The overexpression of oncogenic miR-221 and miR-222 caused by HMGB1 was found to be associated with an increase in malignancy scores (70).

In our analysis, we demonstrated that miR-21 expression levels were significantly increased in the serum of PTMC patients with various factors predictive of a poor prognosis, including bilateral and multifocal lesions and metastatic lymph nodules. Previous studies have reported that upregulation of miR-21 is associated with various metastatic cancers, including prostate, colon, bladder, lung, breast, esophageal and PTC (29,71-74). In addition, miR-21 is associated with aggressive behaviors and poor survival in some cancers (75-78). Among miR-21 targets that could have a role in PTC metastasis, intercellular cell adhesion molecular-1 (ICAM1) stands out (79). In fact, it is upregulated in PTC, and its expression is correlated with aggressive tumor features such as lymph node metastasis (80). The downregulation of miR-21 in recurrent PTC is therefore in agreement with the reported upregulation of ICAM1 in aggressive PTC. It has been shown that miR-21 participates in the process of cell division, differentiation and apoptosis in oncogenesis $(29,81-83)$.

In order to further confirm the correlation between miRNA expression and poor prognosis, we divided the patients into two groups based on the clinicopathological features associated with poor and good prognoses in postoperative patients with PTMC. The results indicated that miRNA expressions levels were significantly higher in patients with multifocality, ETE and metastatic lymphocyte nodules compared with the matched groups with a good prognosis after surgery. These results further confirmed that expression of miRNAs is significantly associated with tumorigenesis and a poor prognosis in PTMC.

Finally, although circulating miRNAs have been confirmed as molecular markers of diagnosis and poor prognosis in PTMC, there were several controversial issues. Firstly, the identified miRNA expression patterns reported in various studies were not completely identical in PTC, which may be due to differences in regions and race, the heterogeneity of PTC or environmental factors. Secondly, the exact mechanism behind circulating miRNAs and the tumorigenesis of PTMC remains unknown. Therefore, it is important to elucidate further the mechanism of action of miRNAs in PTMC. Thirdly, our study was limited due to the fact that we included a cohort of patients from a single center and that the sample size was small. Finally, we also needed longer-term follow-up for patients to obtain relatively accurate results.

In conclusion, miRNAs could serve as biomarkers to distinguish between malignant and benign thyroid nodules. The combination of miRNAs and US could improve the sensitivity and specificity of diagnosis. miRNAs were found to be significantly associated with a poor prognosis of patients with PTMC and could be used as prognostic molecular markers for patients with PTMC before and after surgery. This study results suggest that circulating miRNAs may be useful as non-invasive molecular biomarkers of diagnosis and prognosis for PTMC, but this should be confirmed with continued follow-up and verified with larger patient samples.

\section{Acknowledgements}

Not applicable.

\section{Funding}

This study was supported in part by grants from the Natural Science Foundation of China (grant no. 81673108), the National Basic Research Program of China (973 Program; grant no. SQ2013CB051164) and the Harbin Science and Technology Project (2016RAXYJO88).

\section{Availability of data and materials}

The analyzed data sets generated during the study are available from the corresponding authors on reasonable request.

\section{Authors' contributions}

YZ, HQ and DX acquired the data and created a draft of the manuscript; YZ, JP and ZY prepared the experimental 
materials and performed the assays; ZY, DX and JS interpreted data, performed the statistical analysis and analyzed the results; LS, HQ and YW revised and approved the final version of the manuscript. All authors read and approved the manuscript and agree to be accountable for all aspects of the research in ensuring that the accuracy or integrity of any part of the work are appropriately investigated and resolved.

\section{Ethics approval and consent to participate}

This study was granted ethical approval by the Institutional Review Board of Harbin Medical University. Written informed consent was obtained from all participants involved in the study. The reference code for the ethical approval was no. HMUIRB20150020.

\section{Patient consent for publication}

Not applicable.

\section{Competing interests}

The authors declare that they have no competing interests.

\section{References}

1. Sobin LH: Histological typing of thyroid tumours. Histopathology 16: 513, 1990.

2. Bann DV, Goyal N, Camacho F and Goldenberg D: Increasing incidence of thyroid cancer in the commonwealth of pennsylvania. JAMA Otolaryngol Head Neck Surg 140: 1149-1156, 2014.

3. Burgess JR and Tucker P: Incidence trends for papillary thyroid carcinoma and their correlation with thyroid surgery and thyroid fine-needle aspirate cytology. Thyroid 16: 47-53, 2006.

4. La Vecchia C, Malvezzi M, Bosetti C, Garavello W, Bertuccio P, Levi F and Negri E: Thyroid cancer mortality and incidence: A global overview. Int J Cancer 136: 2187-2195, 2015.

5. Noguchi S, Yamashita H, Uchino S and Watanabe S: Papillary microcarcinoma. World J Surg 32: 747-753, 2008.

6. Qu H, Sun GR, Liu Y and He QS: Clinical risk factors for central lymph node metastasis in papillary thyroid carcinoma: A systematic review and meta-analysis. Clin Endocrinol (Oxf) 83: $124-132,2015$.

7. Luo Y, Zhao Y, Chen K, Shen J, Shi J, Lu S, Lei J, Li Z and Luo D: Clinical analysis of cervical lymph node metastasis risk factors in patients with papillary thyroid microcarcinoma. J Endocrinol Invest: Jun 6, 2018 (Epub ahead of print). doi: 10.1007/s40618-018-0908-y.

8. Frates MC, Benson CB, Doubilet PM, Kunreuther E, Contreras M, Cibas ES, Orcutt J, Moore FD Jr, Larsen PR, Marqusee E and Alexander EK: Prevalence and distribution of carcinoma in patients with solitary and multiple thyroid nodules on sonography. J Clin Endocrinol Metab 91: 3411-3417, 2006

9. Marchetti I, Iervasi G, Mazzanti CM, Lessi F, Tomei S, Naccarato AG, Aretini P, Alberti B, Di Coscio G and Bevilacqua G: Detection of the BRAF(V600E) mutation in fine needle aspiration cytology of thyroid papillary microcarcinoma cells selected by manual macrodissection: An easy tool to improve the preoperative diagnosis. Thyroid 22: 292-298, 2012.

10. Yoon JH, Kim EK, Kwak JY, Moon HJ and Kim GR: Sonographic features and ultrasonography-guided fine-needle aspiration of metastases to the thyroid gland. Ultrasonography 33: 40-48, 2014.

11. Lew JI, Snyder RA, Sanchez YM and Solorzano CC: Fine needle aspiration of the thyroid: Correlation with final histopathology in a surgical series of 797 patients. J Am Coll Surg 213: 188-194, 2011.

12. Kiernan CM, Broome JT and Solórzano CC: The Bethesda system for reporting thyroid cytopathology: A single-center experience over 5 years. Ann Surg Oncol 21: 3522-3527, 2014.
13. Lynam-Lennon N, Maher SG and Reynolds JV: The roles of microRNA in cancer and apoptosis. Biol Rev Camb Philos Soc 84: 55-71, 2009.

14. Garzon R, Calin GA and Croce CM: MicroRNAs in cancer. Annu Rev Med 60: 167-179, 2009.

15. Sempere LF, Freemantle S, Pitha-Rowe I, Moss E, Dmitrovsky E and Ambros V: Expression profiling of mammalian microRNAs uncovers a subset of brain-expressed microRNAs with possible roles in murine and human neuronal differentiation. Genome Biol 5: R13, 2004.

16. Schwertheim S, Sheu SY, Worm K, Grabellus F and Schmid KW: Analysis of deregulated miRNAs is helpful to distinguish poorly differentiated thyroid carcinoma from papillary thyroid carcinoma. Horm Metab Res 41: 475-481, 2009.

17. Tetzlaff MT, Liu A, Xu X, Master SR, Baldwin DA, Tobias JW, Livolsi VA and Baloch ZW: Differential expression of miRNAs in papillary thyroid carcinoma compared to multinodular goiter using formalin fixed paraffin embedded tissues. Endocr Pathol 18: 163-173, 2007.

18. Yip L, Kelly L, Shuai Y, Armstrong MJ, Nikiforov YE, Carty SE and Nikiforova MN: MicroRNA signature distinguishes the degree of aggressiveness of papillary thyroid carcinoma. Ann Surg Oncol 18: 2035-2041, 2011.

19. Nikiforova MN, Chiosea SI and Nikiforov YE: MicroRNA expression profiles in thyroid tumors. Endocr Pathol 20: 85-91, 2009.

20. Haugen BR: 2015 American thyroid association management guidelines for adult patients with thyroid nodules and differentiated thyroid cancer: What is new and what has changed. Cancer 123: 372-381, 2017.

21. Frates MC, Benson CB, Charboneau JW, Cibas ES, Clark OH, Coleman BG, Cronan JJ, Doubilet PM, Evans DB, Goellner JR, et al: Management of thyroid nodules detected at us: Society of radiologists in ultrasound consensus conference statement. Radiology 237: 794-800, 2005.

22. Moon WJ, Jung SL, Lee JH, Na DG, Baek JH, Lee YH, Kim J, Kim HS, Byun JS, Lee DH and Thyroid Study Group, Korean Society of Neuro- and Head and Neck Radiology: Benign and malignant thyroid nodules: US differentiation-multicenter retrospective study. Radiology 247: 762-770, 2008.

23. Haugen BR, Alexander EK, Bible KC, Doherty GM, Mandel SJ, Nikiforov YE, Pacini F, Randolph GW, Sawka AM, Schlumberger M, et al: 2015 American thyroid association management guidelines for adult patients with thyroid nodules and differentiated thyroid cancer: The american thyroid association guidelines task force on thyroid nodules and differentiated thyroid cancer. Thyroid 26: 1-133, 2016.

24. Choi YJ, Baek JH, Baek SH, Shim WH, Lee KD, Lee HS, Shong YK, Ha EJ and Lee JH: Web-based malignancy risk estimation for thyroid nodules using ultrasonography characteristics: Development and validation of a predictive model. Thyroid 25: 1306-1312, 2015

25. Borrelli N, Denaro M, Ugolini C, Poma AM, Miccoli M, Vitti P, Miccoli P and Basolo F: miRNA expression profiling of "noninvasive follicular thyroid neoplasms with papillary-like nuclear features' compared with adenomas and infiltrative follicular variants of papillary thyroid carcinomas. Mod Pathol 30: 39-51, 2017.

26. Yoruker EE, Terzioglu D, Teksoz S, Uslu FE, Gezer U and Dalay N: MicroRNA expression profiles in papillary thyroid carcinoma, benign thyroid nodules and healthy controls. J Cancer 7: 803-809, 2016.

27. Cong D, He M, Chen S, Liu X and Sun H: Expression profiles of pivotal microRNAs and targets in thyroid papillary carcinoma: An analysis of the cancer genome atlas. Onco Targets Ther 8: 2271-2277, 2015

28. Lee JC, Zhao JT, Clifton-Bligh RJ, Gill A, Gundara JS, Ip JC, Glover A, Sywak MS, Delbridge LW, Robinson BG and Sidhu SB: MicroRNA-222 and microRNA-146b are tissue and circulating biomarkers of recurrent papillary thyroid cancer. Cancer 119: 4358-4365, 2013.

29. Sondermann A, Andreghetto FM, Moulatlet AC, da Silva Victor E, de Castro MG, Nunes FD, Brandão LG and Severino P: miR-9 and miR-21 as prognostic biomarkers for recurrence in papillary thyroid cancer. Clin Exp Metastasis 32: 521-530, 2015.

30. Dettmer M, Perren A, Moch H, Komminoth P, Nikiforov YE and Nikiforova MN: Comprehensive MicroRNA expression profiling identifies novel markers in follicular variant of papillary thyroid carcinoma. Thyroid 23: 1383-1389, 2013. 
31. Chou CK, Chen RF, Chou FF, Chang HW, Chen YJ, Lee YF, Yang KD, Cheng JT, Huang CC and Liu RT: miR-146b is highly expressed in adult papillary thyroid carcinomas with high risk features including extrathyroidal invasion and the BRAF(V600E) mutation. Thyroid 20: 489-494, 2010.

32. Chen YT, Kitabayashi N, Zhou XK, Fahey TJ III and Scognamiglio T: MicroRNA analysis as a potential diagnostic tool for papillary thyroid carcinoma. Mod Pathol 21: 1139-1146, 2008.

33. Lawrie CH, Gal S, Dunlop HM, Pushkaran B, Liggins AP, Pulford K, Banham AH, Pezzella F, Boultwood J, Wainscoat JS, et al: Detection of elevated levels of tumour-associated microRNAs in serum of patients with diffuse large B-cell lymphoma. Br J Haematol 141: 672-675, 2008

34. Huang Z, Huang D, Ni S, Peng Z, Sheng W and Du X: Plasma microRNAs are promising novel biomarkers for early detection of colorectal cancer. Int J Cancer 127: 118-126, 2010.

35. Yu S, Liu Y, Wang J, Guo Z, Zhang Q, Yu F, Zhang Y, Huang K, Li Y, Song E, et al: Circulating microRNA profiles as potential biomarkers for diagnosis of papillary thyroid carcinoma. J Clin Endocrinol Metab 97: 2084-2092, 2012.

36. Livak KJ and Schmittgen TD: Analysis of relative gene expression data using real-time quantitative PCR and the 2(-Delta Delta C(T)) method. Methods 25: 402-408, 2001.

37. Cibas ES and Ali SZ: The bethesda system for reporting thyroid cytopathology. Thyroid 19: 1159-1165, 2009.

38. Cappelli C,Pirola I, CumettiD, MichelettiL, Tironi A, GandossiE, Martino E, Cherubini L, Agosti B, Castellano M, et al: Is the anteroposterior and transverse diameter ratio of nonpalpable thyroid nodules a sonographic criteria for recommending fine-needle aspiration cytology?. Clin Endocrinol (Oxf) 63 689-693, 2005

39. Shivapurkar N, Weiner LM, Marshall JL, Madhavan S, Deslattes Mays A, Juhl H and Wellstein A: Recurrence of early stage colon cancer predicted by expression pattern of circulating microRNAs. PLoS One 9: e84686, 2014.

40. Cui EH, Li HJ, Hua F, Wang B, Mao W, Feng XR, Li JY and Wang X: Serum microRNA $125 \mathrm{~b}$ as a diagnostic or prognostic biomarker for advanced NSCLC patients receiving cisplatin-based chemotherapy. Acta Pharmacol Sin 34: 309-313, 2013

41. Selth LA, Townley SL, Bert AG, Stricker PD, Sutherland PD, Horvath LG, Goodall GJ, Butler LM and Tilley WD: Circulating microRNAs predict biochemical recurrence in prostate cancer patients. Br J Cancer 109: 641-650, 2013.

42. Li M, Song Q, Li H, Lou Y and Wang L: Circulating miR-25-3p and miR-45la may be potential biomarkers for the diagnosis of papillary thyroid carcinoma. PLoS One 10: e0132403, 2015.

43. Lee YS, Lim YS, Lee JC, Wang SG, Park HY, Kim SY and Lee BJ Differential expression levels of plasma-derived miR-146b and miR-155 in papillary thyroid cancer. Oral Oncol 51: 77-83, 2015

44. Cantara S, Pilli T, Sebastiani G, Cevenini G, Busonero G Cardinale S, Dotta F and Pacini F: Circulating miRNA95 and miRNA190 are sensitive markers for the differential diagnosis of thyroid nodules in a caucasian population. J Clin Endocrinol Metab 99: 4190-4198, 2014

45. Zhang Y, Xu D, Pan J, Yang Z, Chen M, Han J, Zhang S, Sun L and Qiao H: Dynamic monitoring of circulating microRNAs as a predictive biomarker for the diagnosis and recurrence of papillary thyroid carcinoma. Oncol Lett 13: 4252-4266, 2017.

46. Kim HY, Park WY, Lee KE, Park WS, Chung YS, Cho SJ and Youn YK: Comparative analysis of gene expression profiles of papillary thyroid microcarcinoma and papillary thyroid carcinoma. J Cancer Res Ther 6: 452-457, 2010.

47. Chen X, Ba Y, Ma L, Cai X, Yin Y, Wang K, Guo J, Zhang Y, Chen J, Guo X, et al: Characterization of microRNAs in serum: A novel class of biomarkers for diagnosis of cancer and other diseases. Cell Res 18: 997-1006, 2008.

48. Liu R, Zhang C, Hu Z, Li G, Wang C, Yang C, Huang D, Chen X, Zhang $\mathrm{H}$, Zhuang R, et al: A five-microRNA signature identified from genome-wide serum microRNA expression profiling serves as a fingerprint for gastric cancer diagnosis. Eur J Cancer 47: 784-791, 2011

49. Giordano D, Gradoni P, Oretti G, Molina E and Ferri T: Treatment and prognostic factors of papillary thyroid microcarcinoma. Clin Otolaryngol 35: 118-124, 2010.

50. Mazzaferri EL: Management of low-risk differentiated thyroid cancer. Endocr Pract 13: 498-512, 2007.

51. Zhang Q, Song F, Zheng H, Zhu X, Yao X, Zhang L and Chen K: Association between single-nucleotide polymorphisms of BRAF and papillary thyroid carcinoma in a chinese population. Thyroid 23: 38-44, 2013.
52. Alzahrani AS and Xing M: Impact of lymph node metastases identified on central neck dissection (CND) on the recurrence of papillary thyroid cancer: Potential role of BRAFV600E mutation in defining CND. Endocr Relat Cancer 20: 13-22, 2013.

53. Huang Y, Liao D, Pan L, Ye R, Li X, Wang S, Ye C and Chen L: Expressions of miRNAs in papillary thyroid carcinoma and their associations with the BRAFV600E mutation. Eur J Endocrinol 168: 675-681, 2013.

54. Xing M: BRAF mutation in papillary thyroid cancer: Pathogenic role, molecular bases, and clinical implications. Endocr Rev 28: 742-762, 2007

55. Kim TH, Park YJ, Lim JA, Ahn HY, Lee EK, Lee YJ, Kim KW, Hahn SK, Youn YK, Kim KH, et al: The association of the BRAF(V600E) mutation with prognostic factors and poor clinical outcome in papillary thyroid cancer: A meta-analysis. Cancer 118: 1764-1773,2012.

56. Lin KL, Wang OC, Zhang XH, Dai XX, Hu XQ and Qu JM: The BRAF mutation is predictive of aggressive clinicopathological characteristics in papillary thyroid microcarcinoma. Ann Surg Oncol 17: 3294-3300, 2010

57. Lee X, Gao M, Ji Y, Yu Y, Feng Y, Li Y, Zhang Y, Cheng W and Zhao W: Analysis of differential BRAF(V600E) mutational status in high aggressive papillary thyroid microcarcinoma. Ann Surg Oncol 16: 240-245, 2009

58. Chow SM, Law SC, Chan JK, Au SK, Yau S and Lau WH Papillary microcarcinoma of the thyroid-prognostic significance of lymph node metastasis and multifocality. Cancer 98: 31-40, 2003.

59. Niemeier LA, Kuffner Akatsu H, Song C, Carty SE, Hodak SP, Yip L, Ferris RL, Tseng GC, Seethala RR, Lebeau SO, et al: A combined molecular-pathologic score improves risk stratification of thyroid papillary microcarcinoma. Cancer 118: 2069-2077, 2012 .

60. Ito Y, Miyauchi A, Inoue H, Fukushima M, Kihara M, Higashiyama T, Tomoda C, Takamura Y, Kobayashi K and Miya A: An observational trial for papillary thyroid microcarcinoma in Japanese patients. World J Surg 34: 28-35, 2010.

61. Lee CR, Park S, Kang SW, Lee J, Jeong JJ, Nam KH, Chung WY and Park CS: Is familial papillary thyroid microcarcinoma more aggressive than sporadic form. Ann Surg Treat Res 92: 129-135, 2017.

62. Guo Z, Hardin H, Montemayor-Garcia C, Asioli S, Righi A, Maletta F, Sapino A and Lloyd RV: In situ hybridization analysis of miR-146b-5p and miR-21 in thyroid nodules: Diagnostic implications. Endocr Pathol 26: 157-163, 2015.

63. Rosignolo F, Sponziello M, Giacomelli L, Russo D, Pecce V, Biffoni M, Bellantone R, Lombardi CP, Lamartina L, Grani $G$ et al: Identification of thyroid-associated serum microRNA profiles and their potential use in thyroid cancer follow-up. J Endocr Soc 1: 3-13, 2017.

64. Mohamad Yusof A, Jamal R, Muhammad R, Abdullah Suhaimi SN, Mohamed Rose I, Saidin S and Ab Mutalib NS: Integrated characterization of MicroRNA and mRNA transcriptome in papillary thyroid carcinoma. Front Endocrinol (Lausanne) 9: 158, 2018

65. Zhang J, Liu Y, Liu Z, Wang XM, Yin DT, Zheng LL, Zhang DY and Lu XB: Differential expression profiling and functional analysis of microRNAs through stage I-III papillary thyroid carcinoma. Int J Med Sci 10: 585-592, 2013.

66. Wang Z, Zhang H, He L, Dong W, Li J, Shan Z and Teng W: Association between the expression of four upregulated miRNAs and extrathyroidal invasion in papillary thyroid carcinoma. Onco Targets Ther 6: 281-287, 2013.

67. Han PA, Kim HS, Cho S, Fazeli R, Najafian A, Khawaja H, McAlexander M, Dy B, Sorensen M, Aronova A, et al: Association of braf V600E mutation and microRNA expression with central lymph node metastases in papillary thyroid cancer: A prospective study from four endocrine surgery centers. Thyroid 26: 532-542, 2016.

68. Dai L, Wang Y, Chen L, Zheng J, Li J and Wu X: miR-221, a potential prognostic biomarker for recurrence in papillary thyroid cancer. World J Surg Oncol 15: 11, 2017.

69. Pallante P, Visone R, Croce CM and Fusco A: Deregulation of microRNA expression in follicular-cell-derived human thyroid carcinomas. Endocr Relat Cancer 17: F91-F104, 2010.

70. Mardente S, Mari E, Consorti F, Di Gioia C, Negri R, Etna M, Zicari A and Antonaci A: HMGB1 induces the overexpression of miR-222 and miR-221 and increases growth and motility in papillary thyroid cancer cells. Oncol Rep 28: 2285-2289, 2012. 
71. Shen J, Hruby GW, McKiernan JM, Gurvich I, Lipsky MJ, Benson MC and Santella RM: Dysregulation of circulating microRNAs and prediction of aggressive prostate cancer. Prostate 72: 1469-1477, 2012.

72. Yang L, Feng Y, Qi P, Xu S and Zhou Y: Mechanism of serum miR-21 in the pathogenesis of familial and triple negative breast cancer. J Biol Regul Homeost Agents 30: 1041-1045, 2016.

73. He Y, Jin J, Wang L, Hu Y, Liang D, Yang H, Liu Y and Shan B: Evaluation of miR-21 and miR-375 as prognostic biomarkers in oesophageal cancer in high-risk areas in China. Clin Exp Metastasis 34: 73-84, 2017.

74. Tang D, Shen Y, Wang M, Yang R, Wang Z, Sui A, Jiao W and Wang Y: Identification of plasma microRNAs as novel noninvasive biomarkers for early detection of lung cancer. Eur J Cancer Prev 22: 540-548, 2013.

75. Oue N, Anami K, Schetter AJ, Moehler M, Okayama H, Khan MA Bowman ED, Mueller A, Schad A, Shimomura M, et al: High miR-21 expression from FFPE tissues is associated with poor survival and response to adjuvant chemotherapy in colon cancer. Int J Cancer 134: 1926-1934, 2014.

76. Kjaer-Frifeldt S, Fredslund R, Lindebjerg J, Hansen TF, Spindler KL, Jakobsen A and Danish Colorectal Cancer Group: Prognostic importance of VEGF-A haplotype combinations in a stage II colon cancer population. Pharmacogenomics 13: 763-770, 2012.
77. Xia X, Yang B,Zhai X, Liu X, Shen K, Wu Z and Cai J: Prognostic role of microRNA-21 in colorectal cancer: A meta-analysis. PLoS One 8: e80426, 2013.

78. Guancial EA, Bellmunt J, Yeh S, Rosenberg JE and Berman DM: The evolving understanding of microRNA in bladder cancer. Urol Oncol 32: 41.e31-e40, 2014.

79. Terao M, Fratelli M, Kurosaki M, Zanetti A, Guarnaccia V, Paroni G, Tsykin A, Lupi M, Gianni M, Goodall GJ and Garattini E: Induction of miR-21 by retinoic acid in estrogen receptor-positive breast carcinoma cells: Biological correlates and molecular targets. J Biol Chem 286: 4027-4042, 2011.

80. Buitrago D, Keutgen XM, Crowley M, Filicori F, Aldailami H, Hoda R, Liu YF, Hoda RS, Scognamiglio T, Jin M, et al: Intercellular adhesion molecule-1 (ICAM-1) is upregulated in aggressive papillary thyroid carcinoma. Ann Surg Oncol 19: 973-980, 2012.

81. Zhang JG, Wang JJ, Zhao F, Liu Q, Jiang K and Yang GH: MicroRNA-21 (miR-21) represses tumor suppressor PTEN and promotes growth and invasion in non-small cell lung cancer (NSCLC). Clin Chim Acta 411: 846-852, 2010.

82. Si ML, Zhu S, Wu H, Lu Z, Wu F and Mo YY: miR-21-mediated tumor growth. Oncogene 26: 2799-2803, 2007.

83. Lv C, Hao Y and Tu G: MicroRNA-21 promotes proliferation, invasion and suppresses apoptosis in human osteosarcoma line MG63 through PTEN/Akt pathway. Tumour Biol 37: 9333-9342, 2016. 